\title{
Growth of in vitro Fusarium oxysporum f. sp. niveum in chemically defined media amended with gallic acid
}

\author{
HONG-SHENG WU ${ }^{1,2,3}$, YANG WANG ${ }^{1,2}$, CHAO-YONG ZHANG $^{1,2}$, WEI BAO $^{1,2}$, \\ NING LING ${ }^{1,2}$, DONG-YANG LIU ${ }^{1,2}$ and QI-RONG SHEN ${ }^{1,2, *}$ \\ ${ }^{1}$ College of Resources and Environmental Sciences, Nanjing Agricultural University, Nanjing 210095, China \\ 2 Jiangsu Key Laboratory for Solid Organic Waste Utilization, Nanjing 210095, China \\ ${ }^{3}$ Nanjing University of Information Science and Technology, Nanjing 210044, China
}

\begin{abstract}
Gallic acid was artificially added to the media to grow Fusarium oxysporum f.sp.niveum to investigate its effect on the pathogenic fungus. Results indicate that gallic acid inhibited the growth of $F$. oxysporum f.sp.niveum. The colony diameter, the conidia germinating rate and the conidia yield were reduced by $5.7-$ $22.9 \% \%, 35.8-55.6 \%$ and $38.9-62.2 \%$ respectively. However, the virulence factors by the fungus were stimulated. The activity of pectinase, proteinase and cellulase increased by $12.3-627.8 \%, 11.8-41.2 \%$ and $0.5-$ $325.0 \%$ respectively, while the activity of amylase increased slightly. The results suggest that gallic acid repressed growth but facilitated the relative pathogenicity of invading pathogens.
\end{abstract}

Key terms: Allelopathy; Gallic acid;Fusarium oxysporum f. sp. niveum; Plant-microbe interaction; Virulent factors.

\section{INTRODUCTION}

Watermelon production in the long-term monoculture system has been limited due to frequent occurrence of fusarial wilt by Fusarium. oxysporum f. sp. niveum, which is very difficult to remove from soil once it has been introduced (Booth 1971; Wu et al. $2007 a, b)$. It is the most important soilborne pathogen limiting watermelon production in many areas of the world (Martyn 1996; Wu et al $2007 \mathrm{a}, \mathrm{b})$.

Fusarium species are a genus of harmful fungi that cause vascular disease in plants, such as watermelon, cucumber, tomato, pepper, muskmelon, bean and cotton (Armstrong and Armstrong 1981; Gordon et al. 1997; Nelson 1981). Most of them are toxigenic and produce deleterious secondary metabolites (Marasas et al 1984), damaging host plants through penetration of hyphae into host vascular tissues, secretion of hydrolytic enzymes related to pathogenesis, mycotoxin production and cellular apoptosis of host plant cells in the progression of the infection (Gaumann 1957; Abbas et al. 1997; Bacon et al. 1996; Pavlovkin et al. 2004).

Much study has been focused on the effect of $F$. oxysporum f.sp.niveum on host plants. Little attention has been given to the effect of the host plant on the pathogen. It has been found that many kinds of root exudates and decaying residues (decomposing litter) are phytotoxic as the result of allelochemicals contained in root exudates and decaying residues that have been isolated and identified as organic acids, especially phenolic acids, such as cinnamic, vanillic, coumaric, and ferulic acid (Lee et al. 2006; Hao et al. 2006; Ohno et al. 2001; Yu et al. 2003). Phenolic acids frequently occur in plants, such as hydroxycinnamic acids ester-linked to

\footnotetext{
* Corresponding author: Qi-rong Shen, E-mail: shenqirong@njau.edu.cn, Tel: 0086-25-84395212, College of Resources and Environmental Sciences, Nanjing Agricultural University, Nanjing 210095, China, Jiangsu Key Laboratory for Solid Organic Waste Utilization, Nanjing 210095, China
} 
polysaccarides and large amounts of simple phenolic acids are released during the aerobic catabolism of lignin (Kuwahara 1980; Toms \& Wood 1970). The effects of root exudates and decaying residues on methanogenic microbial communities on rice or maize roots and in the rhizosphere (Lu et al 2004; Baudoin et al. 2003), bacterial community composition (Landi et al. 2006; Sturz 2006), microbial biomass (Sung et al. 2006), stimulation of ginseng root exudates on growth of Phytophthora cactorum and Pythium irregulare (Nicol et al. 2003), rhizobacterial populations (Nehl et al. 1997; Sturz and Christie 2003) and fungal species abundantly rich in the desert (Mandeel 2002) have been studied.

Some studies have found that root exudates might initiate and manipulate biological and physical interactions between roots and soil organisms, and thus play an active role in root-microbe communication (Bais et al. 2004). However, the role of specific compounds from root exudates or decaying plant residues in plant-microbe interaction is almost unknown, though artificially applied chemicals, such as ferulic, caffeic and vanillic acid added to the soil to test for the effects of phenolic acids on microbial biomass and populations had been discussed (Sparling et al. 1981; Blum 1997).

Higher plants synthesize various secondary metabolites including tannic acid and its derivatives, such as ellagic or gallic acid (Lin et al. 2004). Gallic acid (3,4,5trihydroxybenzoic acid,) may be considered as one of the simplest models for natural organic matter (Quici et al. 2008) and is one of the organic acids found in plants that exhibit activity against the bacteria Sallmonella typhi and Staphycococcus aureus and other pathogenic microbes (Chanwitheesuk et al. 2007; Hasegawa et al. 2008). It is a precursor of lignin in cell walls and can be hydrolyzed from lignin by tannase (Trevino-Cueto et al. 2007). It has been widely studied as an antioxidant (Lin et al. 2004; Chanwitheesuk et al. 2007; Hasegawa et al. 2008; Soong and Barlow 2006; Abdelwahed et al. 2007). However, little is known about the immediate effect of gallic acid on $F$. oxysporum f.sp.niveum, i.e. relationships between gallic acid and $F$. oxysporum f. sp. niveum.

Our purpose of this study was to investigate the potential effect of artificially applied gallic acid on the growth and virulence factors by Fusarium oxysporum $\mathrm{f}$. sp. niveum during plant-microbe interactions to evaluate potential risk of gallic acid-driven pathogens to host plants and humans.

\section{METHODS AND MATERIALS}

\subsection{Pathogen strains and chemicals}

Fusarium oxysporum f.sp. niveum (FON) was obtained from the Laboratory of PlantMicrobe Interactions, Nanjing Agricultural University, China. Gallic acid and the other main chemicals used in the experiment were obtained from the Sigma Co. (St. Louis, MO, USA).

\subsection{Measurement of FON colony growth}

A 5-mm agar plug taken from a 7-day-old PDA (potato dextrose agar) culture was inoculated into the center of a plate and incubated at $28{ }^{\circ} \mathrm{C}$ for 7 days(d). Colony diameter was measured in three directions on each plate after incubation for 3 and $7 \mathrm{~d}$.

\subsection{Assessment of conidial germination}

To determine the effect of gallic acid on conidial germination, FON was grown in $2 \%$ water agar. A 5-mm agar plug taken from a 7-day-old PDA culture was inoculated in a liquid culture and incubated at $28{ }^{\circ} \mathrm{C}$ for $7 \mathrm{~d}$. The broth was filtered to collect conidia. Conidial suspension was diluted to $\leq 200$ conidia per millimeter with sterile distilled water. Some $0.1 \mathrm{ml}$ of the diluted suspension was spread on plates and incubated at $28{ }^{\circ} \mathrm{C}$ for $3 \mathrm{~d}$. The number of colonies was counted daily.

\subsection{Determination of sporulation}

Sporulation was determined following the growth of Fusarium oxysporum f.sp.niveum (as described above) in Bilay and Joffe's 
medium (Booth, 1971), with minor modifications (4.0 g CMC-Na instead of 15 g CMC, pH adjusted to 4 with $2 \mathrm{~mol} \mathrm{~L}^{-1}$ $\mathrm{HCl}$ ). After incubation for $7 \mathrm{~d}, 0.1 \mathrm{ml}$ of culture broth, diluted to $10^{-5}-10^{-7}$, was spread onto PDA. Plates were incubated at $28{ }^{\circ} \mathrm{C}$ in the dark for $4 \mathrm{~d}$, after which colonies were counted and converted to the number of conidia in a liquid culture.

\subsection{Measurement of biomass production and enzyme activity}

Fusarium oxysporum f.sp.niveum was grown in $100 \mathrm{ml}$ conical flasks filled with $30 \mathrm{ml}$ potato dextrose broth adjusted to $\mathrm{pH}$ 4.5 with 2 mol. $\mathrm{L}^{-1} \mathrm{HCl}$ and was inoculated with a 5-mm agar plug taken from a 7-dayold PDA culture. Cultures were incubated in a shaker $(170 \mathrm{rpm})$ at $28^{\circ} \mathrm{C}$ for $7 \mathrm{~d}$. Fungal biomass (dry weight) was determined after filtration and drying at $80^{\circ} \mathrm{C}$ for $12 \mathrm{~h}$, when constant weight was achieved. Culture filtrate was used for enzyme assays.

Protease activity was assayed as described by Tseng and Mount (1974). One unit of enzyme activity was defined as a 0.001 increase in absorbance per minute under the assay conditions. Pectinase activity (mainly polygalacturonase) was assayed by the DNS method (Silva et al. 2005). One unit of enzyme activity was defined as the amount of $\beta$-galacturonic acid hydrolyzed from pectin per minute under the assay conditions. Cellulase activity was also determined by the DNS method (Berlin et al. 2005). One unit of cellulase activity was defined as the amount of enzyme that produced $1 \mu \mathrm{mol}$ of reduced sugar per minute under the above assay condition. Total amylase activity was assayed by the DNS method (Murado et al. 1997). One unit of amylase activity was defined as the amount of enzyme that releases $1 \mathrm{mg}$ of reducing sugars (glucose equivalents) per minute under the above assay conditions.

\subsection{Extraction and assay of mycotoxin}

Mycotoxin production (mainly fusaric acid) was determined following growth in
Richard's medium (Gaumann 1957), as described above, but with a $12 \mathrm{~h}$ photoperiod under fluorescent light for $35 \mathrm{~d}$. Broth was acidified to $\mathrm{pH} 2$ with $2 \mathrm{~mol} \mathrm{~L}^{-1} \mathrm{HCl}$, mixed with an equal volume of ethyl acetate, vigorously shaken for $2 \mathrm{~min}$, allowed to settle for $30 \mathrm{~min}$ and the organic phase removed. After repeating this procedure 5 times, the organic phase was centrifuged for $10 \mathrm{~min}$ at $5000 \mathrm{~g}$. The supernatant was dried and condensed at $\leq 40^{\circ} \mathrm{C}$. The dried residue was redissolved in $5 \mathrm{ml}$ of ethyl acetate and the $\mathrm{OD}_{268}$ (Matsui and Smith 1988) was determined by UV spectrophotometry (UV120-02 spectrophotometer Shimadzu, Japan).

\subsection{Experimental design and statistical analysis of data}

Based on our preliminary experiments, studies were carried out using five concentrations of gallic acid: 0, 50, 100, 200 , and $400 \mathrm{mg}$. $\mathrm{L}^{-1}$. The control was 0 $\mathrm{mg} . \mathrm{L}^{-1}$ of gallic acid, but with $2 \mathrm{ml}$ of sterilized methyl alcohol-ethyl acetate instead of gallic acid because gallic acid dissolves in a mixture of methyl alcoholethyl acetate. Gallic acid solution was filter-sterilized by a $0.22 \mu \mathrm{m}$ pore membrane (Millipore). Data were analyzed by Microsoft Excel ${ }^{\mathrm{TM}}$. The values were represented as the mean of three replicates $($ mean \pm SD) for each treatment. One way ANOVA was used and comparison of means were conducted when significant difference was tested by Duncan's multi range LSD at $\mathrm{p}<0.05$.with SPSS version 11.5 (SPSS Co., IL.USA).

\section{RESULTS}

\subsection{Effect of gallic acid on biomass and colony growth}

Biomass of Fusarium oxysporum f.sp.niveum was significantly stimulated by gallic acid in a liquid culture, but inhibited its colony growth on PDA plates. Compared to the untreated control, the dry weight of mycelia increased by 70.0-121.0\% (Fig. 1), the colony diameter decreased by 5.7 $22.9 \%$ (Fig. 2). 


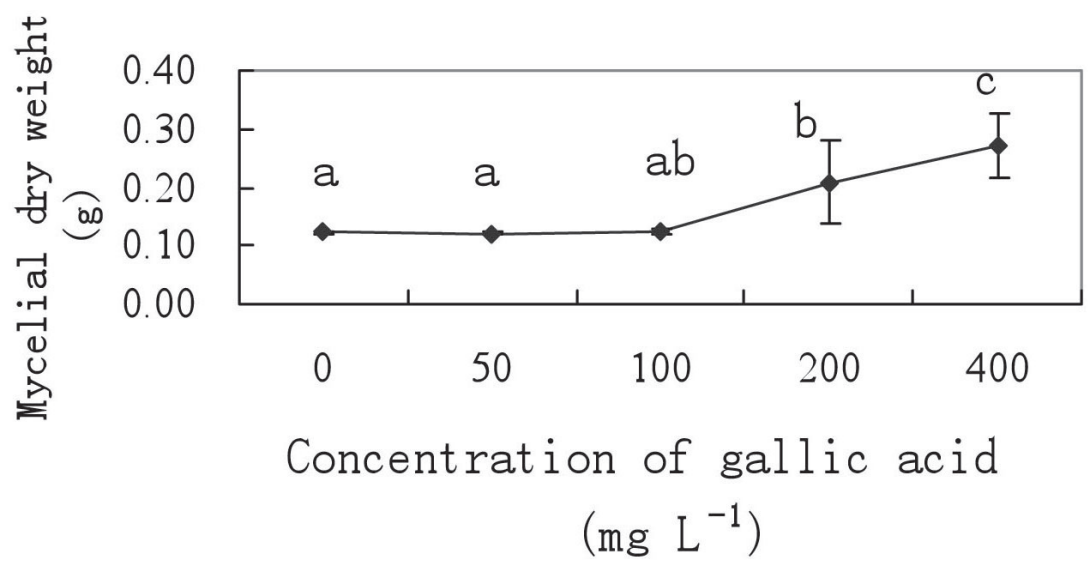

Figure 1: Effect of gallic acid on biomass of Fusarium oxysporum f. sp. niveum. Bars indicate standard deviation of three replicates. $(\mathrm{F}=0.465, \mathrm{n}=4, \mathrm{p}<0.05)$

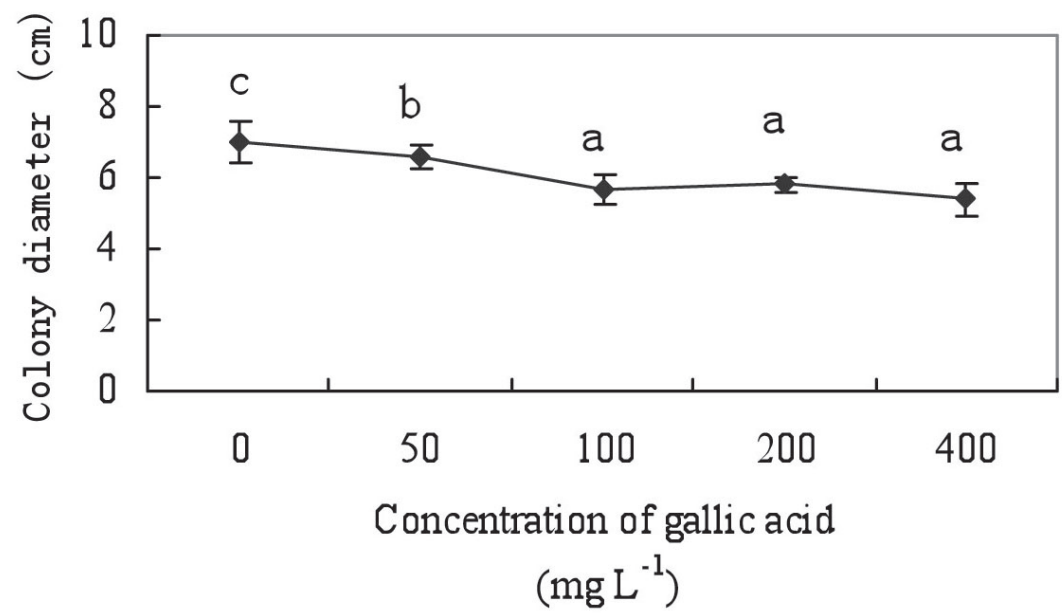

Figure 2: Effect of gallic acid on colony growth of Fusarium oxysporum f. sp. niveum. Bars indicate standard deviation of three replicates. $(\mathrm{F}=1.536, \mathrm{n}=4, \mathrm{p}<0.05)$

\subsection{Effect of gallic acid on conidia germination and sporulation}

Conidia germination on a plate and conidia formation in a liquid culture was significantly inhibited. The number of germinating conidia was reduced by 35.8 $55.6 \%$ (Fig. 3), while the number of conidia produced declined by 38.9-62.2\% (Fig. 4).

\subsection{Effect of gallic acid on mycotoxin production}

Mycotoxin production of Fusarium oxysporum f.sp. niveum in a liquid culture was significantly inhibited by gallic acid in a concentration-dependent manner. The yield of mycotoxin was decreased by 2.4$59.8 \%$ compared with control (Fig. 5).

3.4 Effect of gallic acid on the activities of enzymes related to pathogenesis

Gallic acid stimulated the activity of pathogenic enzymes in the present study. Pectinase activity increased by $12.3-627.8 \%$ in liquid culture (Fig. 6a). A substantial increase of the proteinase activity was observed with treatment by ferulic acid. The proteinase activity initially increased at concentrations of $0-400 \mathrm{mg} \mathrm{L}^{-1}$, with a rise of $11.8-41.2 \%$ but decreased at higher 


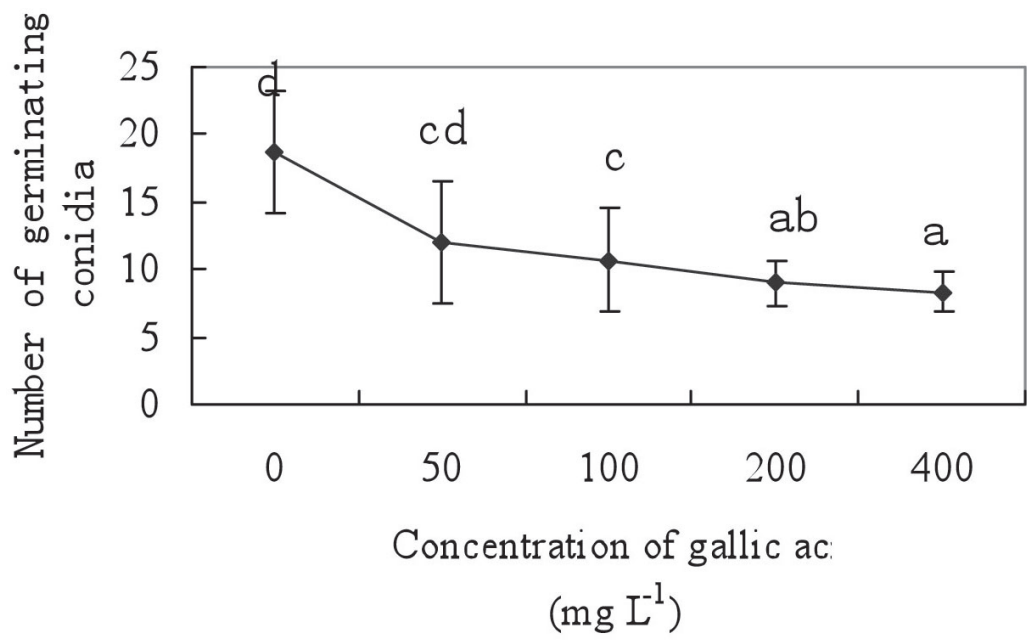

Figure 3: Effect of gallic acid on conidia germination of Fusarium oxysporum f. sp. niveum. Bars indicate standard deviation of three replicates. $(\mathrm{F}=5.846, \mathrm{n}=4, \mathrm{p}<0.05)$

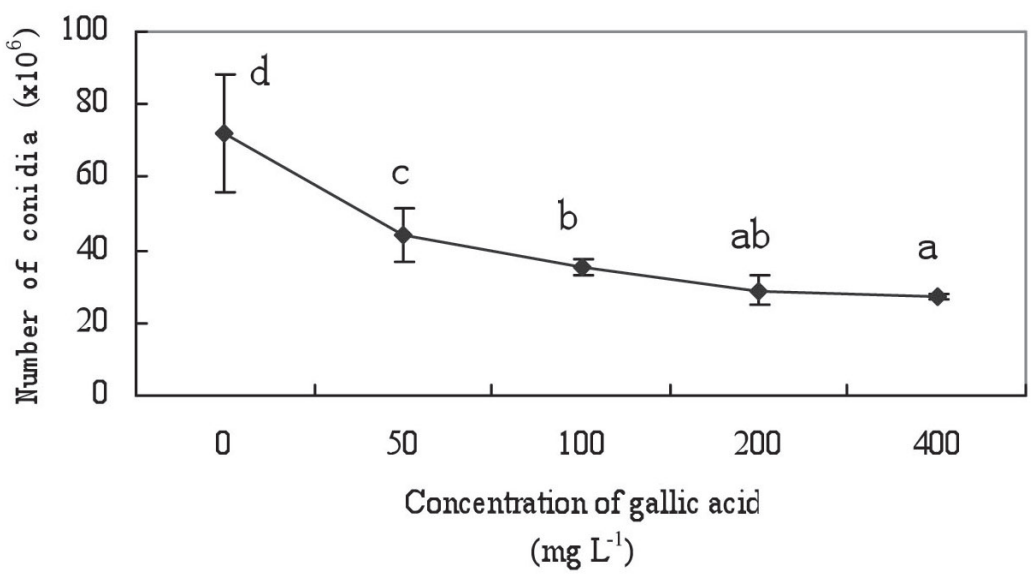

Figure 4: Effect of gallic acid on sporulation of Fusarium oxysporum f. sp. niveum in a liquid culture. Bars indicate standard deviation of three replicates. $(F=11.365, n=4, p<0.05)$

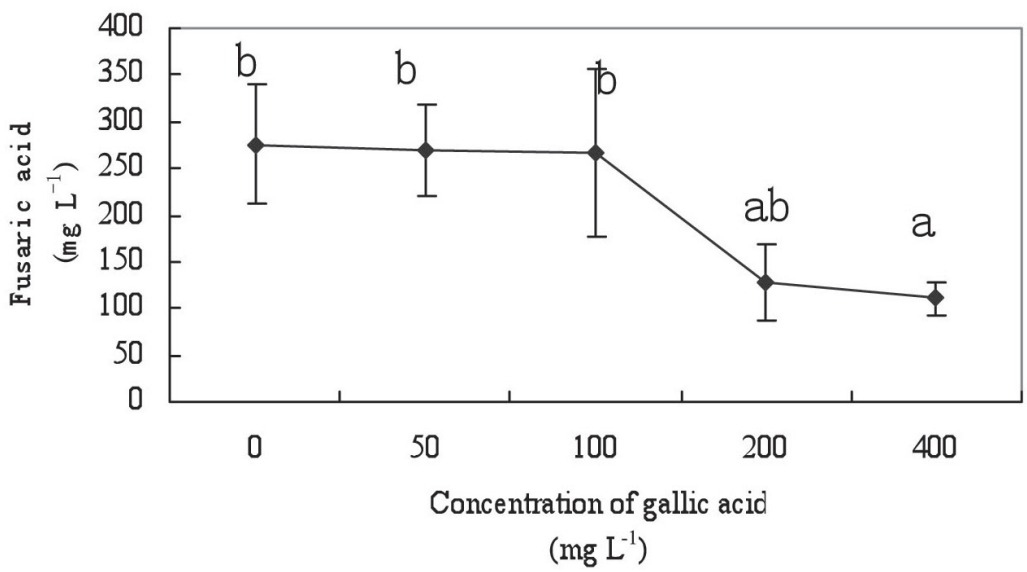

Figure 5: Effect of gallic acid on mycotoxin production of Fusarium oxysporum $\mathrm{f}$. sp. niveum. Bars indicate standard deviation of three replicates. $(\mathrm{F}=18.938, \mathrm{n}=4, \mathrm{p}<0.05)$ 


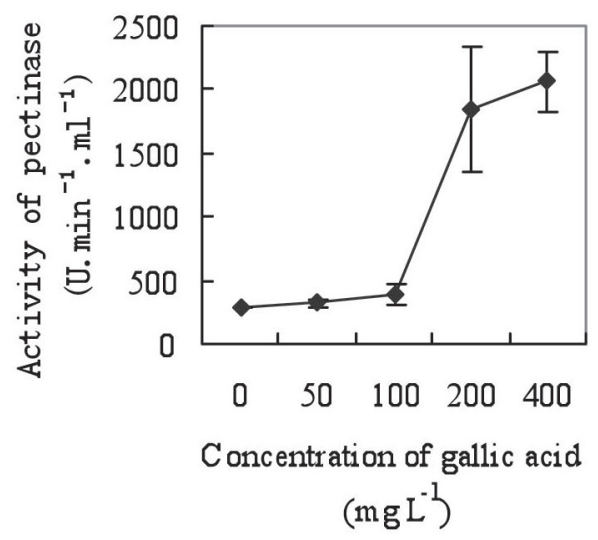

a. pectinase

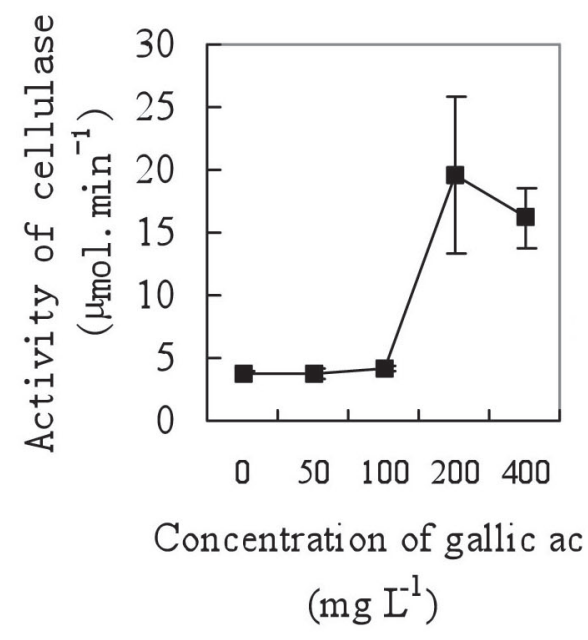

c. cellulase

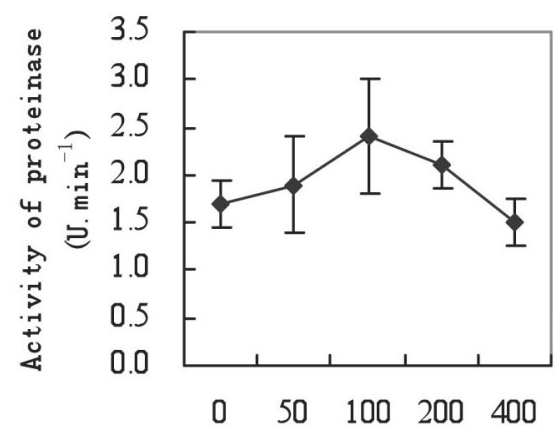

Concentration of gallic acid $\left(\mathrm{mg} \mathrm{L} \mathrm{L}^{-1}\right)$

b. proteinase

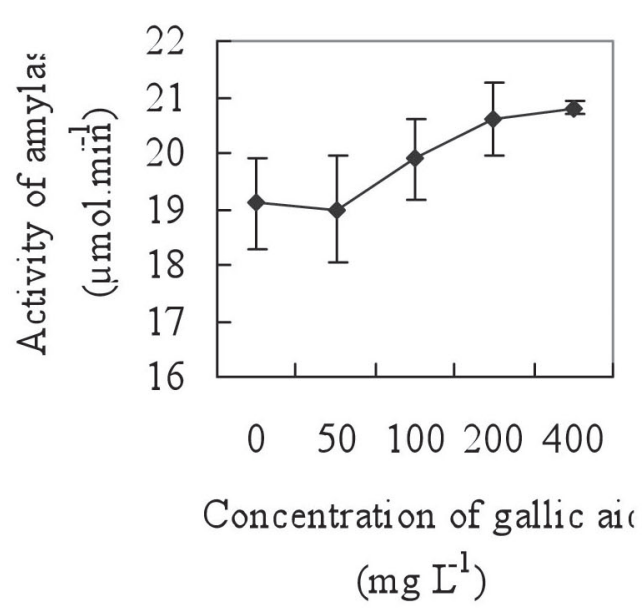

d. amylase

Figure 6: Effect of gallic acid on activities of different hydrolytic enzymes by Fusarium oxysporum f. sp. niveum in a liquid culture. Bars indicate standard deviation of three replicates.

concentration of gallic acid (Fig. 6b). Stimulation of cellulase activity was obtained with increasing concentrations of gallic acid, with activity increasing by 0.5 $325.0 \%$ (Fig. 6c). A slight increase of cellulase activity was found (Fig. 6d).

\section{DISCUSSION}

Gallic acid is a normal metabolite found in plants, which is often detected in the root exudates and plant-grown soil (Wu et al. $2007 \mathrm{a}, \mathrm{b})$. There are some relationships between gallic acid and soil microorganisms and pathogens that affect the soil microbial community and ecological functions.

In the present study, results showed that the mycelial growth of Fusarium oxysporum f.sp. niveum in plates was inhibited by gallic acid in a concentrationdependent manner, with the colony diameter decreasing by 5.7-22.9\% compared to the control (Fig. 2). However, the mycelial growth of $F$. oxysporum f.sp. niveum in a liquid culture was stimulated, with the mycelial dry weight increasing by 
70.0-121.1\% (Fig. 1). This has also been confirmed by the result that the mycelial growth of the $F$. oxysporum f. sp. albedinis is inhibited by cell wall-bound phenolics in date palm roots (Elmondafar \& Boustani, 2001). This was consistent with coumaric and cinnamic acid inhibition of hyphal growth of $F$. oyxsporum f.sp. niveum (Wu et al. 2007a, b). However, the results are in disagreement with the absence of inhibition of Fusarium spp by gallic acid from Caesalpinia mimosoides Lamk (Chanwitheesuk et al. 2007).

The difference in mycelial stimulation or inhibition between plate and liquid culture results from the physiological mechanisms under the two culture conditions.

In the current study, gallic acid dramatically stimulated conidia germination and formation of the fungus. The conidia germinating rate and the yield of conidia were reduced by $35.8-55.6 \%$ and $38.9-$ $62.2 \%$ respectively (Fig. 3). This was not in accordance with the coumaric acid inhibition of $F$. oxysporum f. sp. niveum (Wu et al. 2007a). Though gallic acid stimulated the biomass of $F$. oxysporum f.sp. niveum in a liquid culture, eventually the growth of the fungus was inhibited due to the simultaneous inhibition of conidia germination and formation.

Furthermore, gallic acid affected the virulence factors and pathogenesis of the fungus. Mycotoxin production was heavily restricted by gallic acid in a concentrationdependent manner (Fig. 5). A fall of mycotoxin production implied a reduction of fungus virulence to the host. This was confirmed by the report that the mycotoxin production of $F$. oxysporum f. sp. niveum was suppressed by coumaric acid (Wu et al. 2007). As a powerful defense, mycotoxin is produced when FON invade watermelon or other plants, which is an important pathogenic factor causing plant wilting (Gaumann 1957). Moderate fusaric acid (a fusarilal mycotoxin) doses induce apoptosis in saffron, while high fusaric acid doses stimulate necrosis (Leili \& Behboodi 2006). However, gallic acid increased pathogenic enzyme activities. In this study, the activity of pectinase, proteinase, and cellulase increased by $12.3-627.8 \%, 11.8-41.2 \%$ and
0.5-325.0\% respectively (Fig. 6), while the activity of amylase was slightly elevated. This indicates that gallic acid enhances the virulence of $F$. oxysporum f. sp. niveum against the host. This is in accordance with cinnamic acid increasing pathogenic enzyme activity by $F$. oxysporum f. sp. niveum (Wu et al. 2007b). Other virulence factors equally important for FON are the enzymes related to pathogenesis. Pectinases and cellulases of phytopathogenic fungi stimulate the infection process in many plant diseases. They facilitate the penetration of the fungus into the plant by the hydrolytic cleavage of polymers (pectic substances, cellulose), which constitute the plant cell walls (Fuchs et al. 1965). Fusarial fungi damage host plants through penetration of hyphae into host vascular tissues, secretion of hydrolytic enzymes related to pathogenesis, and mycotoxin production in the progression of the infection (Fuchs et al. 1965).

\section{CONCLUSIONS}

Gallic acid inhibited Fusarium oxysporum f. sp. niveum in this investigation, which might be responsible for host resistance against the pathogen during biotic stress.

\section{ACKNOWLEDGEMENTS}

This work has been financially supported by the Jiangsu Key Lab for Solid Organic Waste Utilization (2007001).

\section{REFERENCES}

ABDELWAHED A, BOUHLEL I, SKANDRANI VALENTI K, KADRI M, GUIRAUD P, STEIMAN R, MARIOTTE AM, GHEDIRA K, LAPORTE F, DIJOUX-FRANCA MG \& CHEKIR-GHEDIRA L (2007) Study of antimutagenic and antioxidant activities of Gallic acid and 1,2,3,4,6pentagalloylglucose from Pistacia lentiscus Confirmation by microarray expression profiling, Chemico-Biological Interactions 165 1-13

BAUDOIN E, BENIZRI E \& GUCKERT A (2003) Impact of artificial root exudates on the bacterial community structure in bulk soil and maize rhizosphere, Soil Biol. Biochem. 35(9) 1183-1192

BERLIN A, GILKES N, KILBURN D, BURA R, 
MARKOV A \& SKOMAROVSKY A (2005) Evaluation of novel fungal cellulase preparations for ability to hydrolyze softwood substrates-evidence for the role of accessory enzymes, Enzyme and Microb. Tech. 37 175-184

BOOTH C (1971) The Genus Fusarium, Commonwealth Mycological Institute, Reading, London, England, pp. 160-192

CHANWITHEESUK A, TEERAWUTGULRAG A, KILBURN JD \& RAKARIYATHAM N (2007) Antimicrobial gallic acid from Caesalpinia mimosoides Lamk. Food Chem. 100 1044-1048

ELMONDAFAR D \& BOUSTANI M (2001) Cell wallbound phenolic acid and lignin contents in date palm as related to its resistance to Fusarium oxysporum, Bio. Plant. 44(1) 125-130

FUCHS A, JOBSEN D \& WOUTS H (1965) Arabanases in Phytopathogenic Fungi, Nature 206 714-715

GAUMANN E (1957) Fusaric acid as a wilt toxin, Phytopathology. 47 342-357

HAO ZP, WANG Q, CHRISTIEA P \& LI XL (2006) Allelopathic potential of watermelon tissues and root exudates, Sci. Horti. DOI: 10.1016/ j.scientia.2006.12.030

HASEGAWA T, TAKANO F, TAKATA T, NIIYAMA M, \& OHTA T (2008) Bioactive monoterpene glycosides conjugated with gallic acid from the leaves of Eucalyptus globules, Phytochemistry 69 747-753

KUWAHARA H (1980) Metabolism of lignin-related compounds by bacteria in lignin biodegradation: Microbiology, Chemistry and Potential Applications, CRC Press, New York, 2, 146

LANDI L, VALORI F, ASCHER J, RENELLA G, FALCHINI L \& NANNIPIERI P (2006) Root exudates effects on the bacterial communities, $\mathrm{CO}_{2}$ evolution, nitrogen transformations and ATP content of rhizosphere and bulk soils, Soil Bio. Biochem. 38(3) 509-516

LEE JG, LE, BY \& LEE HJ (2006) Accumulation of phytotoxic organic acids in reused nutrient solution during hydroponic cultivation of lettuce (Lactuca sativa L.), Sci. Horti, 110(2) 119-11128

LEILI D \& BEHBOODI S (2006) Fusaric acid induces apoptosis in saffron root-tip cells: roles of caspase-like activity, cytochrome c, and $\mathrm{H}_{2} \mathrm{O}_{2}$, Planta, 225 223-234

LIN HC, CHEN PC, CHENG TJ, CHEN RLC (2004) Formation of tannin-albumin nano-particles at neutral $\mathrm{pH}$ as measured by light scattering techniques, Anal. Biochem 325 117-120.

LU YH \& CONRAD R (2005) In Situ Stable Isotope Probing of Methanogenic Archaea in the Rice Rhizosphere, Science, 309(5737) 1088-1090

MANDEEL M (2002) Microfungal community associated with rhizosphere soil of Zygophyllum qatarense in arid habitats of Bahrain, J. Arid Environ. 50 665-681

MARASAS WFO (1984) Toxigenic Fusarium species, In: The Pennsylvania State University Press, University Park, PA, pp. 328

MARTYN RD (1996) Fusarium wilt of watermelon, In: Compendium of Cucurbit Diseases, T. A, Zither, D. L. Hopkins, and C. A. Thomas, Eds. The American Phytopathology Society, St. Paul, MN, pp13-14

MATSUI H \& SMITH W (1988) Quantitative analysis of fusaric acid in the cultural filtrate and soybean plants inoculated with Fusarium oxypsorum var. redolens, $J$. Rakuno Gakuen Univ. (Natural science), 13 159-167

MURADO MA, GONZÁLEZ MP, TORRADO A \& PASTRANA LM (1997) Amylase production by solid- state culture of Aspergillus oryzae on polyurethane foams. Some mechanistic approaches from an empirical model, Proc. Biochem. 32 35-42

NEHL DB, ALLEN SJ, BROWN JF, (1997) Deleterious rhizosphere bacteria: an integrating perspective, Appl. Soil Ecol. 5(1) 1-20

NICOL RW, YOUSEF L, TRAQUAIR JA \& BERNARDS MA (2003) Gingsenosides stimulate the growth of soilborne pathogens of American gingseng, Phytochemistry 64(1) 257-264

OHNO S, TOMITA-YOKOTANI K, KOSEMURA S, NODE M, SUZUKI T, AMANO M, YASUI K, GOTO T, YAMAMURA S \& HASEGAWA K (2001) A species-selective allelopathic substance from germinating sunflower (Helianthus annuus L.) seeds, Phytochemistry 56(6) 577-581

PAVLOVKIN J, MISTRIK I \& PROKOP M (2004) Some aspects of the phytotoxic action of fusaric acid on primary Ricinus roots, Plant, Soil and Environ. 50(9) $397-401$

QUICI N, LITTER MI, BRAUN AM, OLIVEROS E (2008) Vacuum-UV-photolysis of aqueous solutions of citric and gallic acids, J. Photochem. Photobiol. A: Chem, doi: 10.1016/j.jphotochem.2008.01.008

SILVA D, MARTINS ES, SILVA RDA \& GOMES E (2005) Production of pectinase by solid-state fermentation with Penicillium viridicatum RFC3, Proc. Biochem. 40 2885-2889

SOONG YY \& BARLOW PJ (2006) Quantification of gallic acid and ellagic acid from longan (Dimocarpus longan Lour.) seed and mango (Mangifera indica L.) kernel and their effects on antioxidant activity, Food Chem. 97 524-530

STURZ V (2006) Bacterial root zone communities beneficial allelopathies and plant disease control, Inderjit and K.G. Mukeji (eds.), Allelochemicals: Biological control of plant pathogens and disease, Springer, Netherlands, pp123-142

SUNG K, KIM J, MUNSTER CL, CORAPCIOGLU MY, PARK,S, DREW MC \& CHANG YY (2006) A simple approach to modeling microbial biomass in the rhizosphere, Ecol. Mod. 190 277-286

TOPAKAS E, KALOGERIS E, KEKOS D, MACRIS BJ \& CHRISTAKOPOULOS (2003) Bioconversion of ferulic acid into vanillic acid by the thermophilic fungus Sporotrichum thermophile, Lebensm-Wiss.u. Technol, 36 561-565

TOMS A \& WOOD JM (1970) The degradation of transferulic acid by Pseudomonas acidovorans. J Microb and Biochem 9137

TSENG TC \& MOUNT MS (1974) Toxicity of endopolygalacturonate, phosphate and protease to potato and cucumber tissue, Phytopathology 64229

TREVINO-CUETO B, LUIS M, CONTRERASESQUIVEL JC, RODRIGUEZ R, AGUILERA A, AGUILAR CN (2007) Gallic acid and tannase accumulation during fungal solid state culture of a tannin-rich desert plant (Larrea tridentata Cov.), Biores. Tech. 98 721-724

WU HS, WASEEM R, LIU DY, WU CL, MAO ZS \& SHEN QR (2007a) Allelopathic impact of artificially applied coumarin on Fusarium oxysporum f.sp.niveum, World J.Microb. and Biotech. 24 1297-1304

WU HS, WASEEM R, FAN JQ, SUN YG, BAO W \& SHEN QR (2007b) Cinnamic Acid Inhibits Growth but Stimulates production of Pathogenesis Factors by in vitro cultures of Fusarium oxysporum f.sp.niveum, J.Agri. and Food Chem. 56(4) 1316-1321 